\title{
Cutting Chai, Jugaad, and Here Pheri: towards UbiComp for a global community
}

\author{
Nimmi Rangaswamy $\cdot$ Nithya Sambasivan
}

Received: 16 March 2010/Accepted: 15 July 2010/Published online: 27 April 2011

(c) The Author(s) 2011. This article is published with open access at Springerlink.com

\begin{abstract}
This paper attempts to re-imagine ubiquitous computing and technologies for populations in resourcepoor, digitally unstable, and diversely literate environments. Extending UbiComp's frame of reference to include any ICT with a ubiquitous presence, we articulate how technologies are adopted, accessed, used, and diffused in three urban slums of India. We showcase important local practices surrounding technology diffusion and their widespread implications for entrenching ICT use through sharing, learning, training, renewing, and extending use and access. We do this by discussing three main processes at the intersection of technology consumption, resource constraints, and cultural production specific to low-income communities in India: Cutting Chai or sharing technology ownership and maintenance to cut costs, Jugaad or workarounds in the face of resource constraints, and Here Pheri or gray market activity that subvert legal business processes. We also suggest a few design principles to provoke new kinds of inquiry and practice in the design and implementation of UbiComp for a global community.
\end{abstract}

Keywords ICT4D · UbiComp · Global UbiComp · UbiComp4D · Urban slums

\footnotetext{
N. Rangaswamy

Microsoft Research India, 196/36, 2 Main, Sadashivnagar, Bangalore 5600080, India

e-mail: nimmir@microsoft.com

N. Sambasivan $(\bowtie)$

Department of Informatics, University of California, Irvine, CA 92617, USA

e-mail: nsambasi@uci.edu
}

\section{Introduction}

8:35 am, July 2009: Mumbai, India. The southwest monsoon is wreaking havoc and the city a sea of water. Officegoers line up in anticipation of the next train, seeking refuge underneath the roof of the Borivali metro station in outer suburban Mumbai. A train arrives in 5 minutes. Everyone scrambles for a spot in an already-cho-a-bloc compartment. Andheri is the next and final station. As the train is about to leave, a milk man scrambles across the platform, catches hold of the door handle, and lets him in. He removes the huge transparent plastic bag, his monsoonfriendly head gear, managing to park his milk can between the rows of human commuters. He reaches for the inner pocket of his shirt for a smaller, blue plastic bag and unwinds the carefully wrapped package. Presto, a multicolored Shanzai mobile phone pops out. He wipes his hands on the dry insides of his shirt and turns on the phone. In a few seconds, he plays Haule Haule, a recent Bollywood hit, and holds the phone against his ear. In that moment for the milkman, the superstar Shah Rukh Khan croons louder than a thousand conversations in the train.

Over the past decade, information and communication technologies have increasingly found a home in the Global South. As technologies migrate and re-home in new locales, they come to be contextually imagined, accepted, modified, and operated. Such trajectories, and indeed users, of technology have enjoyed little scrutiny under the lens of ubiquitous computing - a vision of a technological future of clean and gleaming infrastructures seamlessly providing well-designed services (in the north/west) [7]. An emerging class of literature has presented accounts of technology usage in the south, examples including usage in middleclass homes in Asia [6, 14], technology ecologies of microentrepreneurs [13, 29, 34], and entertainment [42]. What 
would a version of ubiquitous computing, in and for the Global South look like? This paper attempts to re-imagine ubiquitous computing and technologies for populations in low-income, digitally unstable, and diversely literate environments.

In our ethnographic studies in slums of Mumbai and Bangalore, India, we encountered several people like the milk man for whom technology is enmeshed and embedded in the everyday. Certainly, the milkman and his networks present an unusual manifestation of Weiser's original vision. Slums are our sites of investigation. It is estimated that over 1 billion people live in slums or shantytowns worldwide [46]. Slums occupy a symbolically marginal and invisible yet functionally important role in developing cities occupying a high-density service sector. The aim of this paper, then, is to inquire into the meanings, makings, and doings on technologies in slum environments-against a backdrop of unstable infrastructures and resource constraints. As noted previously [8], by looking outside of the research laboratory, we look at developing ecologies of ubiquitous computing rather than imagine one for the future. Our intent here is not to list the differences between the Global North and South; rather, it is to understand technological engagements in the so-called developing world to re-purpose and re-imagine UbiComp research.

In this paper, we make a case for expanding the lens of UbiComp to include two-thirds of the world population living in the developing world. We articulate how ICTs are adopted, accessed, used, and diffused in three urban slums in Mumbai and Bangalore, India. We showcase key local socio-technical practices surrounding ICT diffusion, as a lens to understand implications for entrenching ICT use through sharing, learning, training, renewing, and extending use and access. We include domestic politics, highdensity housing, migration, and informal networking cultures to foreground the intricacies of designing for slum populations with access to ICTs. We also revise the notion of "resource-poverty" within developing economies to highlight the ubiquitous presence and use of technology through a careful balance between consumption and expenditure. These are responses to the challenges of high entry-level costs and prohibitive maintenance routines of ICT ownership and use, via simpler practices like resourcerecycling and informal routes of skill transfer. We observe a global imaginary, a social construction within reach of poor communities through digital media viewership, enhancing needs and desires for technology.

The paper highlights three key processes at the intersection of technology consumption, resource constraints, and cultural production specific to low-income communities in the Global South: Cutting Chai or sharing technology ownership and maintenance to cut costs, Jugaad or workarounds in the face of resource constraints, and Here
Pheri or gray market activity that subvert legal business processes. First, we will briefly describe our field sites and present the three processes in detail. We will then present potential spaces for Global UbiComp research in these low-income settings.

\section{Previous reflections on global technology}

In this section, we briefly trace the history and perspectives in global technology. We then examine global UbiComp against their changing landscape.

\subsection{Digital and other divides}

In the post-industrial society, information started to play a key role in marking the 'discourse of progress' of nation states. "Information societies" were defined as national economies transitioning from those based on material goods to one based on knowledge [15, 16]. Information carried significant economic, political, and cultural activity. With the advent of telecom and Internet, this concept transformed into "networked society" (as coined by sociologist Manuel Castells), defined as "a society where the key social structures and activities are organized around electronically processed information networks" [11]. A combination of computing social and media networks begins to shape prime modes of organizational structures at various levels of society. This concept further morphed into "network capitalism", augmenting existing structural inequalities between the rich and poor nations [19].

Despite the optimism, distribution of information remained elusively unequal within and between nation states as efforts continued to theorize, problematize, and resolve the growing gap. In 2003, the World Summit on the Information Society (WSIS) came together to bridge what was the growing gap between rich and poor countries through the spread of information technology and access. This belief is significantly guided by the term "digital divide", a construct most frequently used to describe unequal ICT access patterns across nations [25]. The dominant notion of 'the divide' is a dichotomous portrayal between the information-rich and the information-poor and per capita access to ICTs. Simply put, it means "you either have ICT access or don't, you either have connectivity or don't" [40]. However, this notion has come under scrutiny through more sophisticated models of mediating social norms shaping the individuals' engagements with ICTs. Yet, the digital divide still remains a popular pre-occupation with non-governmental organizations, development policymakers, and G-8 summiteers [18]. World Bank economists Fink and Kenny argue the obvious divide in per capita access to telecommunications, and the Internet has 
widened in absolute terms. However, in relative terms, developing countries show faster rates of growth in network development suggesting with current ICT growth rates developing countries are already "digitally leapfrogging" the developed world'(ibid pp 1). Today, some of the poorest countries are able to attract private capital in telecommunications. Tele-density is increasing at an accelerated pace in developing economies (India added 22.88 million mobile subscribers only in November 2010) pointing to not only a changing digital gap but also different architectures of use among populations in these economies.

\subsection{ICT4D}

Visions of digital divide have shaped a growing body of work called Information and Communication Technologies for Development (ICT4D), which investigates and designs technological systems for communities in developing countries to improve access, adoption, and effective use of technologies in their lives (The World Bank's infoDev site catalogs hundreds of information and communications technologies (ICT) projects [24]. Heeks traces the recent explosion of ICTD to the 1998 World Development report from the World Bank for highlighting the role of information, knowledge and ICTs in development and the G8 Digital Opportunities TaskForce in 2000 for setting an agenda for action on ICT4D [22]. Burrell and Toyama define ICT4D as broadly involving a consideration of human and societal relations with the technological world and specifically consider the potential for positive socioeconomic change through this engagement [10]. Heeks points to an "ICTD 2.0", as a significant departure from the telecenter/Personal Computer model to mobile phonebased solutions [22]. A shift in focus on the ground realities and conditions in developing nations has spurred the redefining and meaning of technology access and use. This also meant disentangling notions of impoverished ICT users and use leading to a nuanced understanding of their needs, wants, aspirations, and dreams of social mobility.

\subsection{A turn in UbiComp}

Weiser's original vision of UbiComp called for an invisible, seamless, and ubiquitous set of computational components that allow for information processing in everyday objects and activities [44]. This notion was revised by Bell and Dourish, calling attention to a messy "UbiComp of the present," in their examination of high-tech, high-income ubiquitous environments in Korea and Singapore [7]. Unconventional environments (in the margins) for UbiComp have also been explored by Mainwaring et al. [30] in their study of infrastructure disconnectors, and by
LeDantec [28] and Roberson [35] in their research on homeless populations in the United States. However, these still remain the exception than the norm. Computational devices have steadily penetrated into the home and the hearth in the Global South, largely ignored by the UbiComp community (except for a handful of ICT research in designing infrastructures for resource-constrained environments, such as AirJALDI [1], DakNeT [32], WiLDNeT [31], and efforts such as GlobiComp [20] and UbiComp4D [38]). The past decade has shown that the Global South spends considerably on ICT acquisition, comparable to high-income economies generating a turn of interest to the 'unsaturated emerging markets'. Fisk and Kenny [18] argue, "By concentrating on the number of phones and computers and the number of Internet users, should we ask if there is a digital divide? The answer is yes: Just look at the number of users (computers, hosts, or mobile phones) per capita." They also counter the argument stating while it took about 45 years for the share of the world's TVs that were in developing countries to reach the proportion that would be expected given their income share, the time lag for the World Wide Web is significantly shorter. Invented in 1991, the Internet saw proportionate usage within 12 years.

People in developing nations are already at the interface of ubiquitous telecom availability, access, and use. UbiComp for a global community is poised to understand the use and appropriation of technologies by previously ignored populations who could benefit from this engagement.

\section{Field and method}

\subsection{Method}

Our research in the slums of Mumbai focused on the organization of social and informational resources critical for persons managing low-cost enterprises (e.g., small shops or services). In Bangalore, we focus on domestic labor, as a profession and chore, and its organization of spatial and informational resources. In order to focus solely on technological use and provide inspiration for design, we exclude gender differences factoring into technology ownership and use. The overlapping domains of domesticity and livelihood in low-income communities offer an overarching framework to study adoption and use of technology. We gauge tensions in the nature of information sources and exchange, and explore notions of trust and privacy in these communities. Finally, we map appropriations of traditional and new media and communication technologies.

We used a repertoire of ethnographic methods for eliciting data-participant observation, semi-structured interviews, surveys, photograph diaries, and profile building. 
All interviews were audio-recorded and anonymized. Ethnographic observations provided a depth understanding of the relationship and intersections between urban slum infrastructures, everyday routines and technology use of residents. Surveys and scenarios were used to understand neighborhood information sources and gauge social networks and connections Photograph diaries documented everyday life at work, home, and play (especially on weekends). Twenty-two informants in Bangalore and 10 in Mumbai were recruited through snowballing, and compensatory gifts, such as utensils and bedspreads, were provided. Out of these, we chose 3 representative subjects as profiles to highlight technology use in the everyday. They are typical slum dwellers sharing similar infrastructural and residential environments and engaged in the informal livelihoods sector for paid work. However, the subjects were atypical in that they were early and quick adopters of technology and clever manipulators of constrained scenarios. We engage with more subject-specific details in our findings/discussion sections. All of the data collection methods we mention contributed to profile building lending robust detailing of everyday routines in technology use.

\subsection{Behraum Baug, Mumbai}

Behram Baug is a mixed (religious, cultural, and economic) community with a radius of three $\mathrm{km}, 10,000$ households, and 50,000 people. Our studies in Mumbai spanned 4 months of investigation, focusing on 7 men and 3 women. All made a living offering small, neighborhoodbased services. Family incomes ranged from Rs. 5,000-8,000 ( 100-170 USD) per month. The three women were 27-35 years old, educated at most up to secondary school, and were married with children. One of them worked as domestic help in nearby upper class home, the second managed a home-based tailoring unit, and the third was a support actor in television. All men were in their mid-thirties, educated up to secondary school, and married with children. Four of them have families in native homes outside the city and sent money back. Five of them owned small businesses (subcontracted tailoring unit, a laundering outfit, a snack and beverage kiosk, a nuts and bolts store, and a mobile store). Two of them offered services: one drove an auto rickshaw in the neighborhood and the other was security personnel for an apartment complex.

\subsection{Ragigudda and Nakalbandi, Bangalore}

Our studies in Bangalore spanned 4 months, with 22 women in the slums of Nakalbandi and Ragigudda. They are mid-sized communities of roughly 2,000 households each. Most residents are migrants from Tamil Nadu and can speak Tamil, Kannada, and sometimes Telugu. Our informant pool in Bangalore was exclusively women whose primary profession was domestic labor. The women varied in age from 20 to 70 years old. Education levels varied from no schooling to 10th-grade dropouts. Average family monthly incomes ranged from Rs. 2,000-6,000 ( 40-120 USD).

\subsection{Slums as sites of UbiComp investigation}

In our planet of 6 billion, roughly 1 billion live in slum habitats. This number is expected to rise to 2 billion by 2030 [46]. United Nations agency UN-HABITAT defines a slum household as one that lacks any of the following five elements: access to improved water, access to improved sanitation, security of tenure, durability of housing, and sufficient living area [45]. Urban migration is one of the root causes of burgeoning cities, especially in the "Global South". They attract thousands of immigrants by the day, owing to increasing deagrarianization due to the promise of urban socioeconomic mobility. These exploding cities are weaving extraordinary new urban networks, corridors, and social hierarchies [1].

The compressed nature of the urban slum sprawl results in tight-knit communities with robust social infrastructures for technology consumption [39]. As noted in [5], the poor tend to spend a substantial amount of money on technology; this is especially highlighted in slum communities [34], where technology ownership constraints are subverted through the process of intermediation [39]. Geographical, cultural, political, and social solidarities mobilize the collective narrative of an "imagined community" (as coined by Benedict Anderson [2]) in overriding actual differences between community members.

Our motivation in studying slum communities is to comprehend the interplay of disordered technological infrastructure and services and their shared cultural understandings affecting socioeconomic behaviors.

\section{Explorations in socio-technical ecologies of slums}

We look to anthropologist Arjun Appadurai's definition of technology landscapes or technoscapes to frame the use and meaning of technology in slum communities [3, 4]. Technoscapes are spaces where a range of technologies interacts and changes conventional patterns of communication behavior connecting previously unconnected social spheres. Conjoined with technoscapes are "mediascapes", referring to the power of electronic capabilities to produce and disseminate information via newspapers, television, and the Internet, allowing local imaginaries of the global. More importantly, the scapes are a fusion of new 
technology homing with local forms of material and informational exchanges and communication flows. This is manifest in urban economies, both formal and informal, through efforts to deal with continual interruptions of mainstream systems that sustain major economic sectors: personalized boreholes, 'non-legal' taps of power, water flow, and satellite access points [22]. Endless improvisation surrounds the distribution of scarce water, sanitation, communications, energy, and transport making it "impossible to ignore techno-social architectures of urban life dominated by and constituted through a giant system of repair and improvisation".

We present below the social layout of the three local terms, Cutting Chai, Jugaad, and Here Pheri, signifying the localizations of repair, use, and consumption behavior of ICT media and technology in slum ecologies. We elucidate by employing a relevant subject profile evocative of a specific term, while each of the three terms may find a certain amount of resonance in all three profiles.

\subsection{Cutting Chai (sharing and pooling)}

Cutting Chai is a well-accepted noun in the city of Mumbai where a cup of Chai or tea is shared among two, three, or even four persons to save costs and get their daily fill of the sweet spicy drink. It may mean small amount of teas to be had on-the-run in a crazy, fast-moving city like Mumbai, or make do with an affordable quantity of an everyday addiction to the liquid. We use the term to broadly suggest the pervasive sharing cultures of consumption behavior among the low-income populations in urban India, particularly for shared telecom usages.

Salma, a busy, single mom, and TV actor-support artiste, lives in a one-room tenement in Behram Baug beside her mother and sister's house. She is constantly juggling her media possessions. Her media habits fit into her irregular everyday commute time, conducive to small packets of active audio-visual consumption. She juggles between the FM radio, the 1,000+ Bollywood songs and 5 movies loaded on to her expanded mobile phone memory. Her fifth mobile phone is her current favorite because it can hold all her media.

I don't know how. My cousin told me that this small thing that goes here will give you all entertainment.

He got me the memory card and loaded all content. I

believe these circulate among his circle of friends. I

ask him to erase and reload new ones as and when.

Salma has heard of bluetooth but finds little time to even find out if her phone is bluetooth ready. Her cousin brings a steady supply from his technosocial network of persons circulating audio-visual content.
The phone is regularly borrowed by her mother and sister, for calls and for entertainment. Hindi songs are played out loud every evening. Salma is the sole earning member of her family. Talk time is apportioned among the three family members. Sharing of artifacts is fluid, however, governed by existing norms around budgeting and use. Salma's sister, for instance, is not allowed to talk incessantly on the phone. Says Salma,

My sister talks for hours to someone at night and she pretends to be asleep when I walk in. So now I don't give her the phone at nights.

In Bangalore, Lakshmi, a 35-year-old mother of three, shares her DVD player with her neighbor. She originally bought the player on installment during the Diwali festival discount schemes. In 3 years, she is the proud owner of a Chinese-made video player and self-admittedly never visited the movie hall in these years. New movies are available in the market area, also the neighborhood's epicenter for pirated technology. She has learned to operate the device (play, rewind, and fast-forward) on her own. Lakshmi talks about the change:

Now I don't have to spend money on movie tickets.

We are in tune with the latest Tamil movies from

Chennai. I can watch my favorite star Surya's movies whenever I please! I love movies! Who doesn't? But ticket prices are very high, and we cannot afford them. I bought the VCD player on installment in 2008, as soon as I found an extra job as a seamstress.

Everyone in this neighborhood has one. It gives me dignity and pride.

Lakshmi and her neighbor create a financial arrangement whereby they take turns to buy latest Video Compact Discs (low-fi/low-cost form of DVDs). Lakshmi also borrows new movies from other neighbors in the vicinity. Sharing practices ensures non-duplication of videodiscs in the immediate neighborhood to avoid extra expenses.

While technology is improvised, the human infrastructure is leveraged. Sushila, 45, notes, "Sushila: " $M y$ daughter lives in Senji, Tamil Nadu. When she was here last, she put (stored) her name in the phone (Contacts list). I belong to the old generation, and did not attend school. These (technologies) are very difficult to use. So whenever I want to make a phone call, I get my employer to get my daughter's number from the phone and dial the number. She also ends the call once I finish talking. If I am at home, I ask my youngest daughter." A gift economy is visible here; however, favors are reciprocated in any appropriate fashion. For example, no two VCDs are alike in a community - they are always shared in a neighborhood. 
We note several usage practices at play. Lakshmi and her neighbors have perfected a system where they derive more value out of less money in their media consumption. They also build social capital through disk exchange and trading movie reviews. Media technology becomes a site of economic processes intertwined with socio-cultural production, a site for informal exchanges of gossip and thrift.

At the level of the everyday life, it creates several mobilities: the physical mobility allowing free movement of ICT goods transgresses boundaries of legalities, technologies, freight packages, nation-state economies and localities.

ICTs have also invoked the grand narrative of the "imagined community" [2,3] seeking upward socioeconomic mobility, often viewed as consumerism, creating visions of class mobility and material attainment. Notice how Lakshmi talks proudly about her technology possessions. Her neighbor and friend, Rajapriya, 38, interjected one of our interview sessions,

\section{Singapore-elaam nenachi kooda paakamudiyaadu}

[We cannot even think about Singapore]. We don't

have the financial capability to go to foreign coun-

tries. My whole family enjoys the song sequences in

Tamil movies in foreign countries, like Dubai,

America and Singapore. We get to know so much just

sitting in the living room. The tall buildings, the clean

streets, the kids have rosy cheeks. Maybe my

grandson will work there someday.

On a third level, the content of the ICT (often media) also results in locative mobility, in 'watching a world (Singapore, Switzerland, or Spain) go by' bringing a global imaginary into imperfect landscapes of the urban slum dwellers.

\subsection{Jugaad (workarounds)}

In colloquial Hindustani, the term "jugaad" literally means "an arrangement or a work-around, which has to be used because of lack of resources". Jugaad can mean a survival tactic, an innovative fix to a vexed issue that might involve bending the rules, and toppling established economic traditions and social conventions. The term has acquired a much broader meaning-referring to an innovative, lowcost way of doing something-as goods and services are provided in India at a fraction of the cost of those in developed countries). Bijapurkar [10], for instance, paints a broad stroke by using the term to refer to Indian business innovation models. In some ways, it has come to imply creative, low-cost industry in a developing country like India (e.g., renowned director Shekhar Kapoor's encounter with Indian jugaadi, while unlocking and repairing his Blackberry, made headline rounds recently [41]). Our reading of the term jugaad is less ambitious-neither do we refer to the business enterprises in question, nor do we assume that innovation is a compulsory part of the low-cost activity. $\mathrm{We}$, rather, use the term to indicate work-arounds in the face of perennial constraint of resource to execute everyday tasks. These are often new and unusual ways of thinking to solve routine or systemic problems.

Mustaan is an innovative business incubator and a transformed watch-repair guy! He transitioned to mobile phone repair in the last few years while maintaining his wristwatch business and, more importantly, his loyal clients. Born in Behram Baug, Mumbai, he subleased space outside his friend's fast-food outlet and now stocks a variety of mobile phones, accessories, SIM cards and every deal going in the market for pre-paid talk time. He says,

I make further deals with my clients. I don't mind dropping a bit of profit to give that extra discount. It goes a long way in this super competitive talk-time business.

Mustaan's social networks extend beyond his neighborhood reaching the city's gray markets and a bunch of skilled mobile phone repairers. He tells us,

I will never turn away a customer. I will send his phone to a more expansive market in town to get it repaired.

$\mathrm{He}$ is constantly buying old phones from his clients for an active, rotating business with handsets where he matches with other clients in need of used phones. He also buys them not just to re-sell, but to cannibalize and fit its healthy parts into dead or half-alive phones. His business congeals around mobile phone social networks that support a repair ecology linking his neighborhood with the broader market spaces in the city.

Mustaan's jugaad is useful in illuminating several key factors. Constrained resources and tight budgets may lead to creativity. Ultimately, this points to a marked designreality gap-technologies may not necessarily be imagined, purposed, or used as envisioned by their makers. Oftentimes, in low-income communities, the life span of an artifact is lengthened by finding several post-facto uses for it. For instance, electronic items are often repaired and re-used; electronic goods, paper, and plastic items are recycled in the neighborhood recycling plant; dead technologies that are beyond repair are sold in the market for a fraction of the original price. Artifacts also find multiple purposes [38]. Notice how Mustaan has rented the space outside a restaurant and has maximized on real estate by hanging his clocks on the wall, next to an air-conditioner and a towel rack (Fig. 1). In addition to serving as communication devices, mobile phones are used as re-creational devices, as evidenced through film-based ringtones, 
Fig. 1 (Left) Gray ICT products on sale nearby Behram Baug, and (right) Mustaan's shop
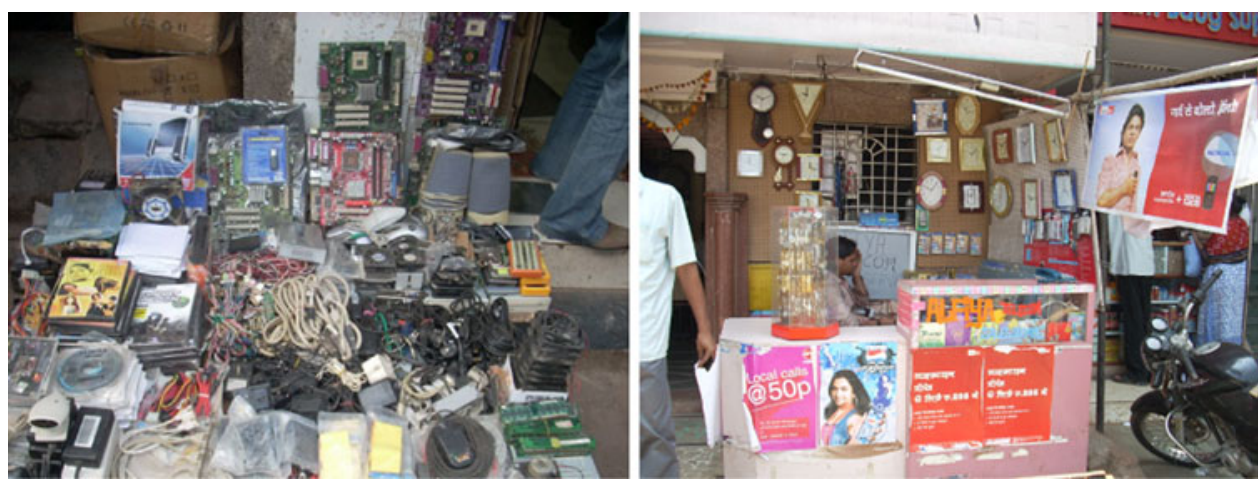

wallpapers, and FM radio. Multi-purpose design also intertwines with financial constraints and offers greater value for money [38]. These issues contrast with the compatibility and interoperability concerns of multiple devices of UbiComp.

\subsection{Hera Pheri (not strictly legal)}

Consider walking into a shop displaying an array of digital devices ranging from cameras, mobile phones, accessories, external hard disks, and the lot. Consider buying these goods, and not being obliged with a bill. The shop keeper tells you,

Madam, this is hera pheri ka maal [pirated goods] with no papers. I cannot bill these formally. I cannot guarantee the brand but I can give you at a huge price difference from the branded one.

There is overwhelming public evidence of information technology existing in nook mom and pop businesses of (re)selling, (re)assembling, (re)cycling and (re)servicing ICTs. It provokes attention toward the flourishing and ubiquitous non-formal or gray markets in India working with sparse and unstable infrastructural resources, kindled by human endeavor and dynamism. In contrast to the popular UbiComp view of infrastructure as given by corporate entities, infrastructures in low-income or resourceconstrained environments often involve the work of several actors and networks in filling gaps in more formal infrastructures, channeling information, communication, and basic necessities of everyday life. Institutional arrangements and ecologies often marginalize low-income communities in providing connections and services allowing a flourishing culture of alternative infrastructures under these severely constrained circumstances. They enable innovative and creative production and distribution channels to circulate content and services.

Piracy and pirated ICTs within informal sectors constitute a stream of business inherently more public and risky, consisting of a furtive web of people connected by social networks. Small operators like street vendors are enabled by flexibility in addressing the lack in many aspects of business; clients in the form of pedestrian traffic, semidurable infrastructure (for easy dismantling and re-location), and ease of attaching additional products and services [29]. At the center is the 'articulate entrepreneur' or the 'processing conduit' for global markets for ICT products, as noted by llahiane and Sherry [23]. Both Mustaan and Salma are looped into this network. Salma is the casual consumer of gray ICT, while Mustaan is a more serious player in this business that Sundaram [43] refers to as a bleeding networking culture:

The pirate network of distribution, which also "bleeds" into other parts of the city, a complex coordinate of media markets, small software and hardware factories, and local shops that interact with customers.

Mustaan's enterprise is an effective distribution channel and delivery point of affordable ICTs to an essentially lowincome public. This offers a model of technology entry, self-driven, organic, and built around popular demands for ICT devices and accessories. In the last few years, India and a host of southeast Asian countries have emerged as attractive destinations for gray markets or parallel economies. These parallel distribution channels and networks result in new post-globalization flows that re-configure markets, dislocating them from national locations and inserting them into the grid of the global economy [27]. The "Global South" is at the vanguard of non-legal media practices, ranging from latest local copies of Dan Brown novels to the action movies from Hollywood, from the Hindi MP3 tracks to the Nokia N-Series rip-off. These local markets coexist with global economies, resulting in inclusive consumerization lending themselves to all socioeconomic strata.

In most cities of the Global South, urban life as the result of continuous efforts at infrastructural improvisation and repair is too overwhelming and visible to be ignored [21]. Underneath, Bangalore's veneer of economic 
prosperity and India's most-wanted IT city, lies a "nonlegal city," invisible at first glance. Roughly $10 \%$ of Bangalore lived in slums in 2001, which is relatively low as compared with other Indian metropolises [26]. However, this figure is contested by many. The Bangalore Development Authority provides for approximately $15-20 \%$ of housing requirements, while another $12-15 \%$ is catered by private developers, increasing the proportion of slum housing to roughly $60 \%$ of Bangalore [27]. Lack of lease documents or ownership certificates makes this number especially difficult to verify.

A vibrant and ubiquitous gray market exists within these confines. Production studios are created by leveraging social networks to pool human and technological capital. Several cyber cafes and mobile repair stores also serve as local production studios. Make-shift vending stalls are created in alliance with grocery stores or mobile phone stores. One of our subjects Subramanian, a 25-year-old man, who recently finished training at a mobile repair store, notes,

Five years ago, I trained as an electrician with my uncle, who owns a store in this neighborhood. I did not make much money once I was self-employed. So lately I have been training with a friend of mine who owns a mobile store. I am learning to do mobile repair. I am also learning to burn VCDs...the store has a PC that we use to burn VCDs in private...We burn the latest Kannada, Tamil and Hindi movies. There is great potential in there, although the competition is stiff.

A new layer of technological imagination has deposited itself over the non-legal slum settlements creating alternate modes and channels for participating in the broader global economy. The gray is tightly yoked to the informal economy of low entry capital, low margins of profit, and good volume of sales in dense slum habitats [33], typically found in the low-income locales in the metropolises of the Global South.

Consider the following story of the VCD, illustrative of the modes, channels, and agents involved in gray industry.

\subsubsection{Production}

Three years ago, residents of the slums of Ragigudda and Nakalbandi did not even dream about VCD players. However, in 2007, the local electronics store in Ragigudda had announced a new installment scheme. They were selling VCD players for Rs. 100 per month for the next 3 years (consider that the average income per family is between Rs. 3,000-5,000). Word spreads about the scheme. The store had picked the right time to market the appliance-Diwali (the Indian festival of lights), when it was traditional to buy new goods. The highly local process of peer influence eventually led roughly $55 \%$ of the households to purchase a VCD player. The rest are on their way. For now, they will leverage their social networks to share the device. None of these players come from reputed companies. They were assembled in Bangalore, with components imported from Singapore. The shopkeeper purchases the components from a relative who lives in Singapore.

\subsubsection{Reproduction}

Any pop culture media piece released for public view, or sometimes in its pre-release stage, is immediately tracked down and copied. This process involves several steps: one takes a video camera to the cinema hall to stealthily tape the film (it is quite funny to see human figures walking across the hall, laughing out loud, and cheering in film videos). Depending on their access, a hacker may also download content from the Internet. Mobile repair shops and cyber cafes double up as pirates, because the price of Internet infrastructure forbids the domestic slum-dweller from subscribing to connections. Reproduction involves substantial infrastructure, often assembled from used parts in practice. Slightly older movies are also ripped from original DVD sources. Next, a cover for the disk sleeve (usually a copy of the poster of the movie) is printed on a color printer. The file is burned in Video CD format using pirated CD-burning software. The end-product is a VCD that competes for market space with an original DVD, costing five times less.

\subsubsection{Re-distribution}

The VCD has shifted the site of the marketplace from air-conditioned showrooms to makeshift banal spaces, such as street corner bazaars or rented spaces. VCDs are sold in trains, railway stations, public monuments, street vendor stalls, and in regular market. It creates a whole new infrastructure and ecology of agents in its marketization. The VCD ripper who travels to cinema halls, the VCD creator, the VCD seller, the player seller, the CD sleeve printer, the $\mathrm{CD}$ cover photograph printer, the innumerable distribution agents, the delivery persons, and the logistics/management persons. Thus, it makes the economy more inclusive, providing several thousand jobs. The effects are profound. What was once regulated to the urban elite, through formal distribution channels and centralized marketplaces, is now decentralized, democratized, and decoupled from the central market. The result is that a significant portion of the urban consumer population is low income, yet striving to be upwardly mobile. 


\section{Spaces for UbiComp4D}

In the above three case studies, we highlighted three sociocultural processes to underscore technology usage, simultaneously mapping them on to existing normative social arrangements $=$ enabling new capabilities, relations, and practices.

The Cutting Chai case illustrates how technology intersperses with cultural principles and financial management. Ownership and use can be either single or collective, signaling the importance of technology in the everyday of low-income households.

In the Jugaad case, technology is adapted and appropriated to make-do with existing resources. It leads to emergent and radical forms of innovation, catering to local needs of the community. In commercial enterprises, a diverse range of skills is required, such as hardware assembling, software services, and staying updated with local needs, such as personalization of media (wallpapers, ringtones, and music in mobile phones, local blockbuster movies for VCDs) and water seepage during monsoons. By outsourcing the product repair hacks, a resource network is created, to deal with contingencies of skill expertise. Infrastructural and interface improvisations surround technology hacks and production, resulting in better market penetration markets, reduced labor costs, and contextually relevant products and services. Various technologies are wired together to create new assemblages for local user capacities distinct from their original patented design. Repair and maintenance practices diffuse via socio-business networks supporting steady enterprise-client relations.

In the third case of Here Pheri, we point to the prominence of informal, social networks of micro-entrepreneurs in exposing and disbursing technology (mobile phone, here) services to its largely low-income consumers. In thinking of slum locales less as information-poor zones and more as multiple, intersecting media zones for communication and information channeling [33], we see how the informal distribution channels are actively brokering technology for effective use. Low-cost technology re-production is not just a local endeavor, but brings together several economic orders, across infrastructures, locations, and legalities.

In each of these cases, we see how technologies slip into active usages only by a circumvention or subversion of formal routes. Nevertheless, they travel through local and culturally acceptable routes. They challenge the traditional UbiComp assumptions of personal and private, seamless and invisible, and above all legal and compliant.

In the following section, we list a few design statements that might provoke new kinds of inquiry and practice in the design and implementation of UbiComp for a global community (for an extended discussion, see [38]).

\subsection{Modernity and development}

'The "aspiration window" (i.e., the window formed from an individual's cognitive world, her zone of "similar", "attainable" individuals) is more meaningful when we ask what the determinants of an aspirations window are, and the effects of aspirations on behavior. Such a lens provides us with an understanding of the broader structural forces of poverty and helps us elicit the idea of development from the locals, as the post-development movement advocates [36].

Our findings suggest that one place to look for local understandings of development is in the idea of modernity. Technology occupies a privileged place in low-income communities, not different from other socioeconomic strata. It is often viewed as an indicator of higher status. The technological imagination is projective, creating visions of class mobility and material attainment [3]. As we note in Lakshmi's case, her ability to own and use a technology gives her much satisfaction. In her friends Rajapriya's case, we see the role of technology in creating imaginaries far beyond the scope of her lived experience. The perpetual consumption of VCD content introduces 'knowledge' of a globalizing India, a world of cosmopolitan role models and visions of overall progress While not all of it may relate to a commonly accepted notion of "welfare," consumption of technologies and mass media pave the way for a global imaginary, and hope for a better future. In today's India modernity or acquiring a place in its sun is not just hope but an evolving reality with a rapidly growing IT sector and its related umbrella of service economy.

"Development" is as much an ideological concept as is its practical concern for actual economic upliftment. The Millennium Development Goals are largely an instrumental equation of development with economic benefit and basic necessities of life, such as health care and clean water. However, socio-cultural impacts of development are often intertwined with the economic, as evidenced in the case of Lakshmi's DVD player usage. While it offers her respite, it has undoubtedly advanced her technology usage skills and allowed her to experience a reality much wider than the one inscribed by her social location. Deconstructing and decompartmentalize development expands the scope of the term "for development" to include an understanding of the place of technology in the social universe of people it hopes to impact and empower. Such an understanding re-purposes development by rendering technology design opportunistic and relevant to the inherent fuzziness in instrumental and non-instrumental uses of technology. 


\subsection{Support heterogeneity}

Instead of asking 'how to design an interface for illiterate consumers' we need to ask 'what skills need to be learned to be able to competently carry out series of simple mobile money related tasks'? [12].

Bell and Dourish [9] note that alternative and contemporary views of ubiquitous infrastructure have messiness in common with each other, in contrast to UbiComp's vision of seamless infrastructures. In low-income communities, heterogeneity is visible everywhere-in remote controls, in bicycle seats, gas stoves, mobile phone covers, languages, and Sari (traditional Indian women's clothing) colors. UbiComp for low-income environments could benefit from understanding the diversity of user ecology—varying informational needs, literacy levels, numeracy levels, or digital literacy levels, across a shared unit as a challenge in the design of shared technologies [38]. The challenge here is to design under resource constraints such as dated technologies, irregular infrastructures, and gray market goods.

As noted in the Cutting Chai case, sharing norms in family and community spaces like kitchens, warehouses, shops, and informal neighborhood spaces extends into usages of technological goods like mobiles, DVDs, and scooters. Although there is shared usage among a set of socially interlinked groups, this may not translate into communal usage across a neighborhood of slums or lowincome habitats. Several models of sharing may exist among different sets of social groups.

Hybrid adoptions and adaptations create varying forms of digital literacy, technology needs, uses, and understandings. Skills needed by Lakshmi in adjusting color and brightness on her television are different from Salma's skills or lack of it, in uploading videos to her phone. So is the behavior of women who is numerate but non-literate storing phone numbers on the walls of her home. By ordering of the numbers in specific ways, she associates persons with phone numbers. These are forms of literacies and ordering rationalities to make sense of the world of fragmentary literacy. Dichotomous models of literate/nonliterate could repudiate the range of nuanced and enabling literacies. We argue that recognizing multiple ways of viewing, understanding, and interacting with the world of-multiple literacies and degrees of familiarity with user interfaces may help in productive design.

\subsection{Low cost, not cheap}

Rohan Samarajiva of LIRNEasia [37] mapped the Indo-Gangetic mobile telecom terrain business innovation, defining a Budget-telecom-network model to be the driver of mind-boggling adoption of phones. The author notes similar innovative models in lateral market penetration that innovate to offer affordable services without compromising on quality. Low cost is not synonymous with bad quality; on the contrary, we argue low-income communities consciously weigh quality.

Evident in our three cases earlier, the low-income communities aspire for smooth, hassle-free technologies that provide value for money. Salma uses a phone with a camera and expandable memory; Lakshmi watches a color television that has a cable connection and is plugged into a DVD player; Mustaan repairs and sells a range of mobile devices; the camera store keeper sells products that are otherwise inaccessible to the low-income consumer because of forbidding prices or trade restrictions. The correlation between income and media expenditure is a clear indicator of why technologies must be low cost to achieve mass impact. Technologies must be affordable beyond initial costs to include maintenance, subscription, repairs, and up-gradation. Instead of introducing costly instrumentation, ubiquitous computing researchers might innovate on existing technologies, such as adding computational capabilities to television, radio sets, and DVD players. Interoperability and linking of devices can help in borrowing and augmenting computational capabilities of neighboring devices.

Our ethnographic data point to the importance of modularity. Salma's phone is constantly fitted with add-ons, such as memory cards, headphones, and mobile covers, as and when she is able to afford them. Lakshmi's television costs her Rs. 15,000 (300 USD), whereas her monthly income is Rs. 2,000 (45 USD). This kind of lop-sided spending is resonant with several other budget regimes among other households in her community. ICT4D projects show a latent impulse to work with the present, in order to deploy scalable applications and make them relevant and useful. While the intent is important, the groundedness misses out the forest for the trees. Low-income communities seem to go to great lengths to acquire quality technology that is symbolically and functionally meaningful in their lives.

The high-tech, high-fidelity technologies of the Global North trigger a corresponding response in the Global South in the form of low-cost, low-fidelity technologies. UbiComp could benefit from remaining alert to such technology trends. Its "proximate future" tense may, in fact, be beneficial for low-income communities. For example, store-and-forward protocols, like DakNet [32] and WiLD$\mathrm{NeT}$ [31], are not only high-quality technologies, but are also appropriate to unconnected technological environments, and at the same time advance the state of 
delay-tolerant networking for the research community at large. The poor as users and not as beneficiaries of technology can substantially reposition UbiComp engagements to be more productive. Such a repositioning also allows for design practices to reflect on ground realities.

\subsection{The gray space}

...Although I belong to and my business is enabled by grey markets... I operate through many markets some of which are legal and licensed... my mobile phone repair business puts me in touch with legal agents of multi-national companies... often I buy branded spare parts to service and repair phones...This market is one that mixes cheap and quality products that is branded and 'China-made'...Infact the china made is itself mixed...we get very good, lowcost and guaranteed products from China...'Mustaan, mobile phone store owner.

The gray is not simply indicative of a zone transacting goods of dubious quality to beat costs and legal processes. It is also not simply a response to the often forbiddingly expensive branded and open market goods. We suggest that gray zones are intersections of the formal and the informal, legal and the illegal and black and white markets. Informal or the gray economy blends with the socio-geographic order of mega-cities in developing economies; the slum is a viscerally evocative space for local production and consumption of media technology. It suggests the arrival of a new creative industry responding to the pulse of a large consumer base eager for technology goodies. These grassroots industries comprise a range of industries requiring low-capital investments catering to a market ignored by legal and formal enterprises.

The viral spread of DVD players in the Bangalore slums, hardly visible 3 years ago, is attributed to the entry of gray market DVD players. Avoidance of prohibitive prices and long queues at the boxoffice and the motivation to consume the latest mass entertainment products resulted in an almost pervasive presence of DVD players. The local scale of production and site of consumption create new developmental conditions. The VCD mega-industry creates several informal distributed outfits employing several thousand workers. Businessmen and agents of gray markets customize products for local relevance and cost. Mustaan is one among many of our subjects in the Mumbai study who belonged and operated via gray markets to service a mixed clientele demanding both low-cost and good-quality goods.

I have clients coming from Nasik (a small tourist town 300 miles from Mumbai) who want branded phones and spare parts to service a local demand for mobile phones and services. Sometimes, I get branded phones for low cost through my networks from the used [second-hand] mobile phone market.

UbiComp needs to contend with the ubiquitous grayness of software and hardware in low-income communities (degrees of grayness may vary, depending on reproduction or re-cycling or re-distribution of hardware or software). Edwards and Grinter point to impromptu interoperability as being a challenge in domestic UbiComp-every device of software must be explicitly written to understand every other type of device or software it may encounter [17]. This challenge becomes even more evident with gray goodssoftware and hardware are manufactured by non-standard, non-compliant organizations.

We are making a case neither to replace nor to support gray technologies but to bring the universe of UbiComp a bit closer to technology consumption practices in the Global South. We do this by foregrounding the creative resourcefulness and utility of gray markets often condemned as black markets viewed through the lens of legalese.

\section{Conclusions}

Prevailing UbiComp explorations are largely focused on high-tech, western environments. If UbiComp has to be a truly global endeavor, it must cater to unfamiliar and nontraditional contexts, across socioeconomic segments. ICTs have percolated into previously unconnected worlds. They are being adopted, adapted, and appropriated in culturally and socially relevant ways. By looking outside of the bounded environs of the practicing UbiComp community, the field can not only enrich its understanding of originary theories and practices, but also explore ways to address new users, uses, and contexts. We have to consider how technologies are mapped onto existing normative social arrangements and how they disrupt, amplify, undermine, or produce new relations. Our ethnographic work in lowincome communities shows interesting practices stemming out of encounters with resource constraints and socio-cultural re-production of everyday technology consumption. Specifically, we discussed Cutting Chai, or pooling and splitting costs, Jugaad or workarounds and improvisations, and Here Pheri or gray market activity. Each of these phenomena point to a range of technosocial activities that challenge traditional assumptions of UbiComp as personal and private, seamless and invisible, and above all legal and compliant. We show that technologies in the urban slums of India are heterogeneous, communal, and gray, but at the same time, they are strong markers of identity and aspiration and comprise a significant portion of low-income budgets. Technologies after all belong to the whole world, 
including the milkman in the Mumbai metro. The challenge for Ubicomp is to understand wherever they may be.

Acknowledgments We wish to thank our informants in Mumbai and Bangalore the Technology for Emerging Markets group, Microsoft Research India and Bonnie Nardi.

Open Access This article is distributed under the terms of the Creative Commons Attribution Noncommercial License which permits any noncommercial use, distribution, and reproduction in any medium, provided the original author(s) and source are credited.

\section{References}

1. AirJaldi Wireless Network. http://summit.airjaldi.com

2. Anderson B (1991) Imagined Communities. Verso Books, London

3. Appadurai A (1996) Modernity at large: cultural dimensions of globalization. University of Minnesota Press, USA

4. Appadurai A (2000) Spectral housing and urban cleansing: notes on millenial Mumbai. Pub Cult 25(3):627-651

5. Banerjee A, Duflo E (2007) Economic lives of the poor. J Econ Perspect 21(1):141-167

6. Bell G (2006) Satu keluarga, satu komputer (one home, one computer): cultural accounts of ICTs in south and Southeast Asia. Des Issues 22(2):35-55

7. Bell G, Dourish P (2007) Yesterdays tomorrows: notes on Ubiquitous computing's dominant vision. Pers Ubiquit Comput 11(2):133-143

8. Berg M (1998) The politics of technology: on bringing social theory into technological design. Sci Technol Hum Values 23(4):456-490

9. Bijapurkar [http://www.bijapurkar.com/successstrategies/ss_state_ of_consumer.php]

10. Burrell J, Toyama K (2009) What constitutes good ICTD research? ITID J 5(3):82-94

11. Castells M (2000) The rise of the network society. The information age: economy, society and culture. In: Chalmers M, MacColl I (eds) Seamful and seamless design in ubiquitous computing, vol 1, 2nd edn, Blackwell, Malden. Technical Report Equator-03-005, 2004

12. Chipchase J (2009) Designing services for financial inclusion. Mobile money transfer conference

13. Donner J (2009) Blurring livelihoods and lives: the social uses of mobile phones and socioeconomic development. Innov Technol Gov Glob 4(1):91-101

14. Donner J, Rangaswamy N, Steenson MW, Wei C (2008) "Express yourself" and "stay together": the middle-class Indian family. In: Katz J (ed) The handbook of mobile communication studies. MIT Press, Cambridge, pp 325-338

15. Drucker P (1969) The age of discontinuity. Heinemann, London

16. Erni JN, Chun SK (2005) Introduction: our Asian media studies? In: Asian media studies: politics of subjectivities. Blackwell Publishing, pp 1-17

17. Edwards K, Grinter R (2001) At home with ubiquitous computing: seven challenges. In: Proceedings of Ubicomp 2001

18. Fisk C, Kenny C (2003) W(h)ither the global digital divide? World Bank, Washington

19. Fuchs C (2010) Class, knowledge and new media. Media Cult Soc 32(1):141-150

20. Globicomp, workshop at UbiComp (2009). http://www.cs.swan. ac.uk/globicomp2009/
21. Graham S, Thrift N (2007) Out of order. Theory Cult Soc 24(3):1-25

22. Heeks R (2008) The ICT4D 2.0 manifesto: where next for ICTs and international development? IPDM working papers http://www.sed.manchester.ac.uk/idpm/research/publications/wp/ di/di_wp42.htm

23. Ilahiane H, Sherry J (2008) Joutia: street vendor entrepreneurship and the informal economy of information and communication technologies in Morocco. J North Afr Stud 13(2):243-255

24. Infodev, http://www.infodev.org

25. James J (2008) Digital divide complacency: misconceptions and dangers. Inf Soc 24(1):54-61

26. Karnataka slum clearance board, http://housing.kar.nic.in/ DOH_KSCB_page.htm

27. Liang L (2006) The other information city. www.t0.or.at/wio/ downloads/india/liang.pdf

28. Le Dantec C, Edwards WK (2008) Designs on dignity: perceptions of technology among the homeless. In: Proceedings of CHI 2008, pp 627-636

29. Lugo J, Sampson T (2008) E-informality in Venezuela: the 'other path' of technology. Bull Latin Am Res 27(1):102-118

30. Mainwaring S, Chang M, Anderson K 2004 "Infrastructures and their discontents Implications for UbiComp. In: Proceedings of UbiComp 2004

31. Patra R, Nedevschi S, Surana S, Sheth A, Subramanian L, Brewer E (2007) In: Proceedings of USENIX NSDI, April 2007

32. Pentland A, Fletcher R, Hasson A (2004) DakNet: rethinking connectivity in developing nations. Computer 37(1):78-83

33. Rangaswamy N (2009) ICT for mesh-economy: case study of an urban slum, IFIP 2009, May 26-28, Dubai

34. Rangaswamy N, Nair S (2009) The mobile phone store ecology in a Mumbai slum community: hybrid networks for enterprise, AiOR09 mobile phones and the developing world pre-conference workshop, Milwaukee, October 2009

35. Roberson J, Nardi B (2010) Survival needs and social inclusion: technology use among the homeless. In: Proceedings of CSCW 2010

36. Roy D (2010) "Aspirations, segregation and occupational choice" (with D. Mookherjee and S. Napel), J Eur Econ Assoc (revised May 2009, forthcoming)

37. Samarajiva R (2010) Key note, ICTs and development: an international workshop for theory, practice and policy, March 12-12, New Delhi, India

38. Sambasivan N, Rangaswamy N, Cutrell E, Nardi B (2009) UbiComp4D: interaction and infrastructure for international development-the case of urban Indian slums. In: Proceedings of UbiComp 2009, pp 155-164

39. Sambasivan N, Cutrell E, Toyama K, Nardi B (2010) Intermediated technology use in developing communities. In: Proceedings of CHI 2010

40. Selwyn N, Gorard S (2010) Digital divide or digital opportunity? The role of technology in overcoming social exclusion in US education. In: Kasi E (ed) Social exclusion: a reader. Rawat Publications, Jaipur

41. Kapur S http://shekharkapur.com/blog/2010/07/a-blackberry-addictdiscovers-grassroots-enterprise-in-india/

42. Smyth T (2010) Where there is a will, there is a way. In: Proceedings of CHI 2010

43. Sundaram R (2010) Pirate Modernity: Delhi's Media Urbanism. Routledge, Oxon

44. Weiser M (1994) The world is not a desktop. ACM Interact $1(1): 7-8$

45. UNSECO (Retrieved on 15 March 2009). http://www.uis. unesco.org/ev_en.php?*ID=6401_201\&ID2=DO_TOPIC

46. UN-Habitat (Retrieved on 15 March 2009). http://www.uis. unesco.org/ev_en.php?*ID=6401_201\&ID2=DO_TOPIC 